\title{
Pay and cost of living data for FDs applying for first hospital training posts
} \section{across the UK}

The BDA has provided information for foundation dentists applying for hospital training posts across the UK, to help them make an informed decision about their future career paths.

Investigating data, they have highlighted the cost living in 13 of the major cities across the UK and mapped it to the total earnings an average trainee will receive over their seven-year training period, to calculate potential local 'purchasing power'.

Hospital Dental Service training posts are a popular consideration for many dentists starting out in their careers, because of the opportunities they offer to get a wide range of skills and experience, early on in dental career.

Competition for places is often fierce, particularly for posts in London and the South East, so the BDA have investigated the data to compare the cost of living in different parts of the UK, compared to pay levels.

Pay levels for a first training post in the HDS in England, Northern Ireland, Scotland and Wales can differ up to $£ 5 \mathrm{~K}$ per year, but the data suggest that considering the costs of living element is also essential to take into account, as this can affect how much it leaves to actually live on.

Peter Dyer, Chair of the BDA's Central Committee for Hospital Dental Services said: 'We know that the decision of where to apply for your first hospital dental services training post is a crucial one, and often a stressful one.

'We investigated these data to help provide clarity on how much you might earn in different parts of the UK, but also to encourage you to think about the cost of living in different parts of the UK, so you

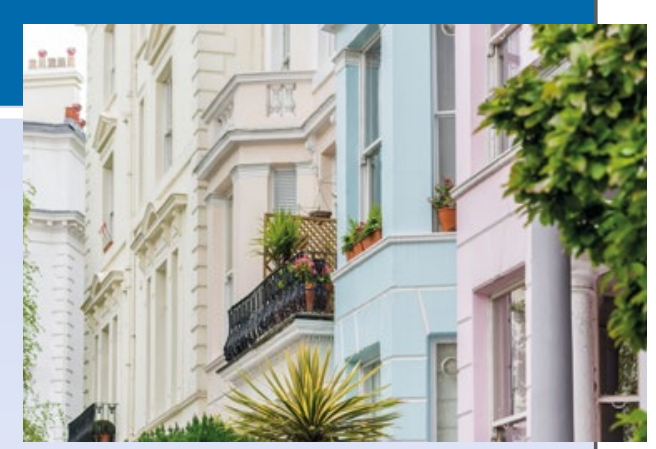

can consider what the best option is for your circumstances.

'At a time when applications for these posts is very competitive, we really encourage you to consider all your options before ranking your preferences, to ensure you choose a hospital post that is right for your career path and right for your financial situation.'

More information can be found at: https://www.bda.org/about-the-bda/ campaigns/pay/Pages/Hospital-DentalService-trainees-pay.aspx. 